\title{
Subungual Squamous Cell Carcinoma of the Thumb Treated by "Function Sparing Approach" Using Contact Radiotherapy (Brachytherapy)
}

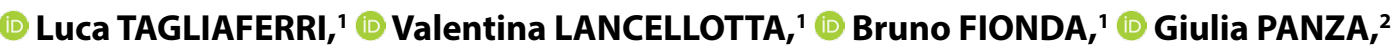 \\ (1) Patrizia CORNACCHIONE, ${ }^{1}$ (b) Giuseppe COLLOCA, ${ }^{1}$ (D) Luigi AZARIO, ${ }^{3}$ (D) Gian Carlo MATTIUCCI, ${ }^{2}$ \\ (1) Maria Antonietta GAMBACORTA, ${ }^{2}$ - Vincenzo VALENTINI ${ }^{2}$
}

\begin{abstract}
'U.O.C. Radioterapia Oncologica, Dipartimento di Diagnostica per immagini, Radioterapia Oncologica ed Ematologia, Fondazione Policlinico Universitario "A. Gemelli" IRCCS, Rome-Italy

${ }^{2}$ U.O.C. Radioterapia Oncologica, Dipartimento di Diagnostica per immagini, Radioterapia Oncologica ed Ematologia, Istituto di Radiologia, Fondazione Policlinico Universitario "A. Gemelli" IRCCS, Università Cattolica del Sacro Cuore, Rome-Italy

${ }^{3}$ U.O.C. Fisica Sanitaria, Dipartimento di Diagnostica per immagini, Radioterapia Oncologica ed Ematologia, Istituto di Fisica, Fondazione Policlinico Universitario "A. Gemelli" IRCCS, Università cattolica del Sacro Cuore, Rome-Italy
\end{abstract}

\begin{abstract}
SUMMARY
A-48-year old man, affected by HIV, working as an electrician, presented a swollen and painful subungual lesion over the distal phalanx of the right thumb with an important limitation to his job. A cutaneous examination of the right thumb revealed an irregular erosive crusted mass formation about $2 \mathrm{~cm} \times 1 \mathrm{~cm}$ size with erythematous changes and complete destruction of the overlying nail plate. There was no evidence of regional lymphadenopathy; the patient was studied with computed tomography that did not show any distant disease. A conservative onychectomy was performed with removal of the lesion and with histological confirmation of SCC. However, after five months, the patient presented local recurrence over the thumb. Amputation was proposed, but the patient declined due to the negative impacts on his job. Thus, contact radiotherapy (i.e., brachytherapy, BT) was proposed. BT was delivered using a customized homemade surface mold with six plastic tubes arranged around. The total delivered dose was 40 Gy delivered in eight fractions, 5 Gy for daily using Iridium-192 High Dose Rate (HDR) source. Four years later, recently, the patient is free from disease and has a complete functionality of the thumb without any limitations in any movement and in his job. The patient only reported a slight sensitivity reduction.

Keywords: Brachytherapy; contact radiotherapy; interventional radiotherapy; thumb carcinoma.

Copyright $\odot$ 2019, Turkish Society for Radiation Oncology
\end{abstract}

\section{Introduction}

In squamous cell carcinoma (SCC) the first-choice treatment is surgery.[1,2] However, radiotherapy is often used as an alternative or in combination with surgery with an organ and function preserving intent, such as in head and neck cancer, anal cancer and cervical cancer.[3,4,5] In this case report we aim to highlight the chance to use this therapy also for function sparing approach in skin cancer.

\section{Case Report}

A-48-year old man, affected by HIV, working as an electrician, presented a swollen and painful subungual lesion over the distal phalanx of the right thumb with an important limitation to his job.

U.O.C. Radioterapia Oncologica,

Dipartimento di Diagnostica per immagini,

Radioterapia Oncologica ed Ematologia,

Fondazione Policlinico Universitario "A. Gemelli" IRCCS

Rome-Italy

E-mail: bruno.fionda@yahoo.it 
A cutaneous examination of the right thumb revealed an irregular erosive crusted mass formation about $2 \mathrm{~cm} \times 1 \mathrm{~cm}$ size with erythematous changes and complete destruction of the overlying nail plate (Fig. 1a). There was no evidence of regional lymphadenopathy; the patient was studied with thorax and abdomen CT that did not show any distant disease.

A conservative onychectomy was performed with removal of the lesion and with histological confirmation of SCC. However, after five months, the patient presented local recurrence over the thumb. Amputation was proposed, but the patient declined due to the potential negative effects on his job. Thus, contact radiotherapy (brachytherapy, BT) was proposed. BT was delivered using a customized home-made surface mold (Fig. 2a) with six plastic tubes arranged around. The total delivered dose was 40 Gy delivered in eight fractions, 5 Gy for daily using Iridium-192 High Dose Rate (HDR) source. In figure $2 \mathrm{~b}$, the dose distribution is presented. Four years later, recently, the patient is free from disease and has a complete functionality of the thumb without limitation in any movement and in his job (Fig. 1b). The patient only reported a slight sensitivity reduction.

\section{Discussion}

Subungual SCC is a rare malignancy. The diagnosis of subungual SCC is often delayed or missed because of the nonspecific clinical presentation. In fact, for its variable clinical presentation, it can be often misdiagnosed with the benignant condition, such as a chronic paronychia, onychomycosis, pyogenic granuloma, sub- ungual wart, glomus tumor, ingrown nail, subungual exostosis, chronic osteomyelitis, traumatic dyschromia, keratoacanthoma, and melanotic nevus.

Several factors reportedly predispose individuals to subungual SCC, including HPV, chronic trauma, chronic inflammation, chronic infection, ionizing radiation, solar radiation, tar, arsenic or other mineral exposure and immunosuppression.[6] Usually, definitive surgery consists of the amputation of the phalanx, causing aesthetic damage and functional limitation.[7] In fact, this finger has a primary role in grabbing and carrying out normal daily activities, $[8,9]$ especially in the case of local recurrences, radiation therapy represents a valid alternative to re-excision or amputation both with potentially functional impairment.[10,11] Contact radiotherapy is a radiation treatment where the radioactive source is placed temporarily in contact the tumor site[12,13] and allows to target the dose on the target volume, while sparing the surrounding normal tissues because of a rapid fall-off representing a valid therapeutic option, it has been widely demonstrated in other peculiar anatomical districts. $[14,15]$ This allows us to minimize the side effects of radiotherapy and allows such an approach to be also considered for frail and elderly patients. [16,17]

\section{Conclusion}

The best therapeutic choice for thumb skin cancer is challenging, considering the absence of the standardized guidelines. Contact radiotherapy (brachytherapy) could be considered a valid alternative to surgery, with organ and function sparing results.
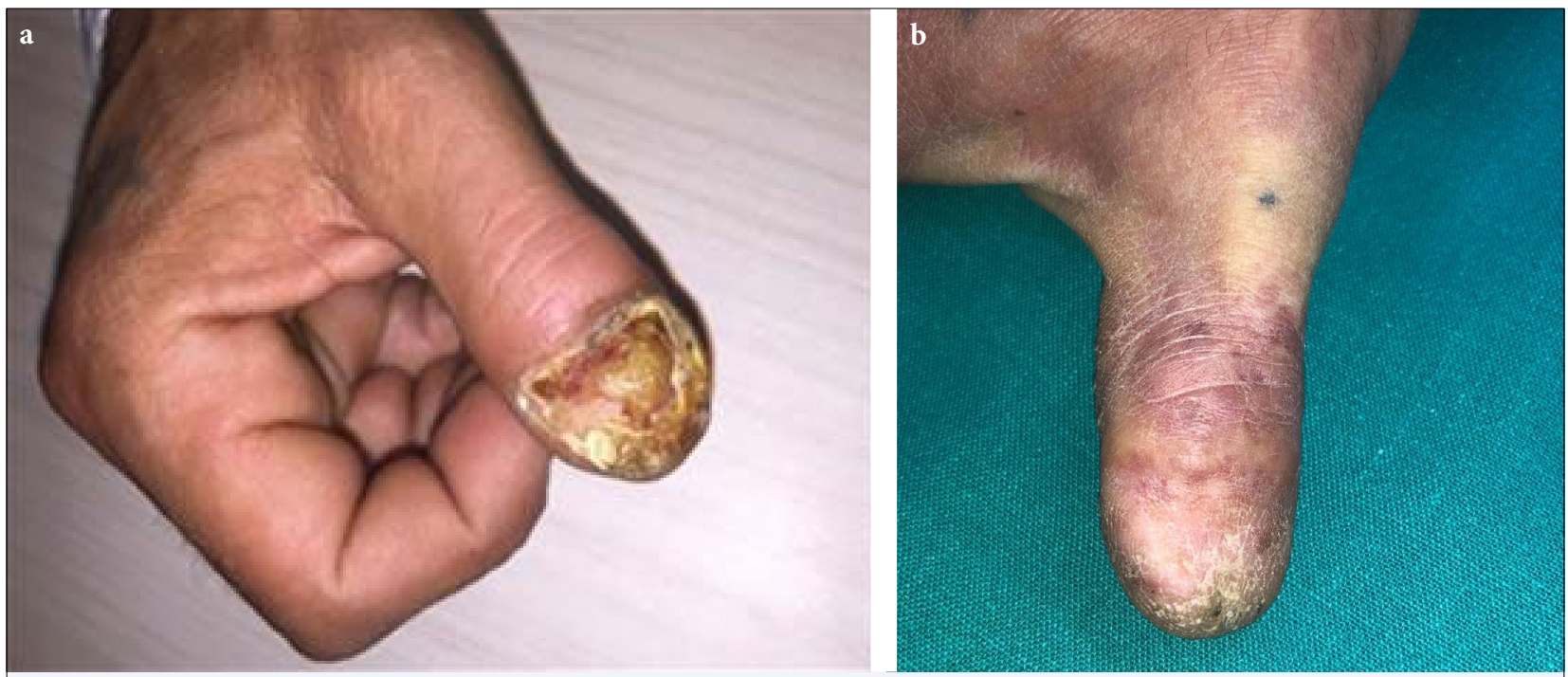

Fig. 1. (a) Thumb at diagnosis, (b) thumb after 4 years. 

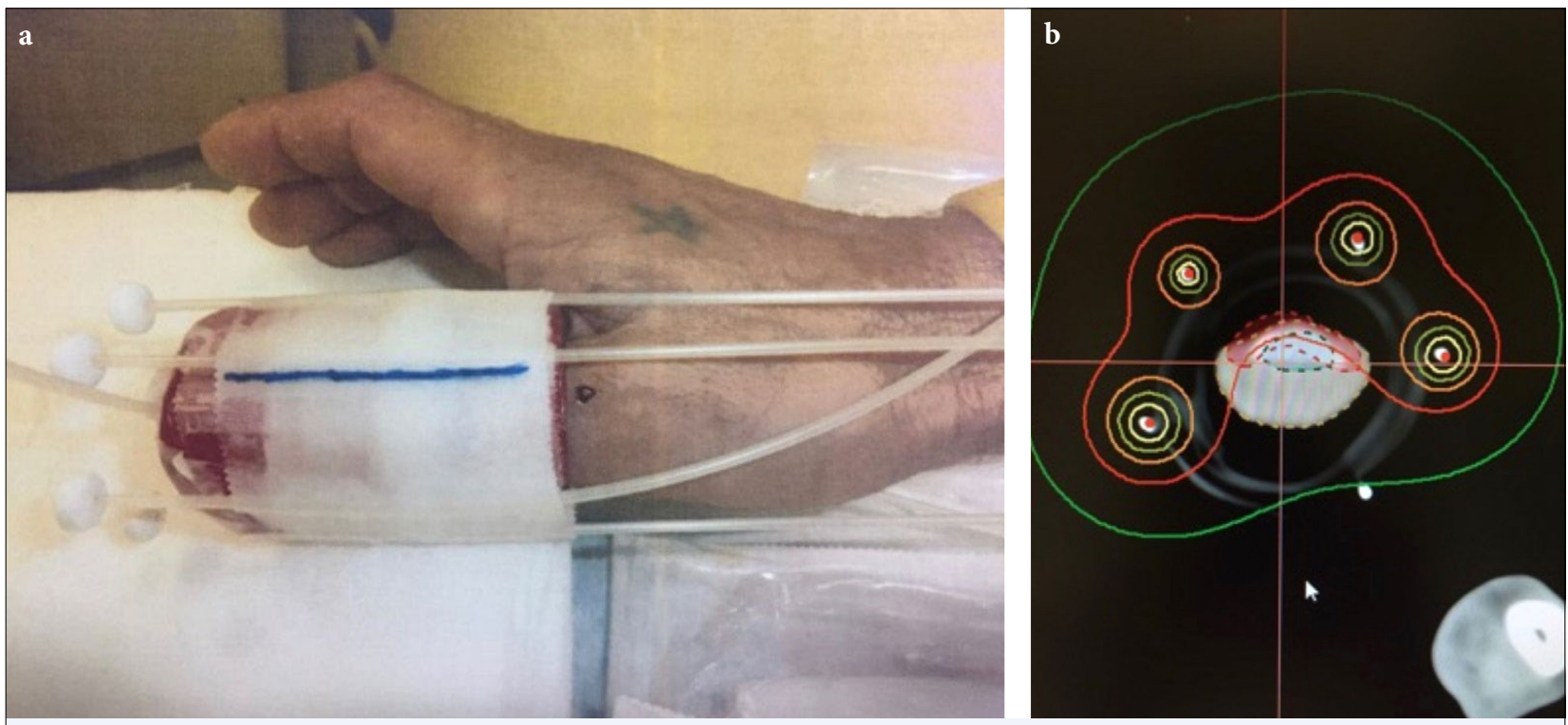

Fig. 2. (a) Customized home-made surface mold, (b) Dose distribution.

Peer-review: Externally peer-reviewed.

Conflict of Interest: None declared.

Authorship contributions: Concept - L.T.; Design - V.L.; Supervision - L.A., G.C.; Data collection \&/or processing P.C.; Analysis and/or interpretation - None; Literature search - G.P.; Writing - B.F., G.C.M.; Critical review - M.A.G., V.V.

\section{References}

1. Lecerf $\mathrm{P}$, Richert B, Theunis A, André J. A retrospective study of squamous cell carcinoma of the nail unit diagnosed in a Belgian general hospital over a 15-year period. J Am Acad Dermatol 2013;69(2):253-61.

2. Dalle S, Depape L, Phan A, Balme B, Ronger-Savle S, Thomas L. Squamous cell carcinoma of the nail apparatus: clinicopathological study of 35 cases. Br J Dermatol 2007;156(5):871-4.

3. Tagliaferri L, Bussu F, Fionda B, Catucci F, Rigante M, Gambacorta MA, et al. Perioperative HDR brachytherapy for reirradiation in head and neck recurrences: single-institution experience and systematic review. Tumori 2017;103(6):516-24

4. Tagliaferri L, Manfrida S, Barbaro B, Colangione MM, Masiello V, Mattiucci GC et al. MITHRA - multiparametric MR/CT image adapted brachytherapy (MR/ CT-IABT) in anal canal cancer: a feasibility study. J Contemp Brachytherapy 2015;7(5):336-45.

5. Banerjee R, Kamrava M. Brachytherapy in the treatment of cervical cancer: a review. Int $J$ Womens Health 2014;6:555-64.
6. Tambe SA, Patil PD, Saple DG, Kulkarni UY. Squamous Cell Carcinoma of the Nail Bed: The Great Mimicker. J Cutan Aesthet Surg 2017;10(1):59-60.

7. Bussu F, Tagliaferri L, Mattiucci G, Parrilla C, Dinapoli $\mathrm{N}$, Miccichè $\mathrm{F}$, et al. Comparison of interstitial brachytherapy and surgery as primary treatments for nasal vestibule carcinomas. Laryngoscope 2016;126(2):367-71.

8. Wong TC, Ip FK, Wu WC. Squamous cell carcinoma of the nail bed: Three case reports. J Orthop Surg 2004:12(2):248-52.

9. Tagliaferri L, Pagliara MM, Boldrini L, Caputo CG, Azario L, Campitelli M, et al. INTERACTS (INTErventional Radiotherapy ACtive Teaching School) guidelines for quality assurance in choroidal melanoma interventional radiotherapy (brachytherapy) procedures. J Contemp Brachytherapy 2017;9(3):287-95.

10. Wadhwa SS, Duggal N. A Customized Finger Brachytherapy Carrier. J Indian Prosthodont Soc2014;14(3):326-9.

11. Arterbery VE, Watson AC. An electronic brachytherapy technique for treating squamous cell carcinoma in situ of the digit: a case report. BMC Res Notes 2013;6:147.

12. Tagliaferri L, Budrukkar A, Lenkowicz J, Cambeiro M, Bussu F, Guinot JL, et al. ENT COBRA ONTOLOGY: the covariates classification system proposed by the Head \& Neck and Skin GEC-ESTRO Working Group for interdisciplinary standardized data collection in head and neck patient cohorts treated with in- 
terventional radiotherapy (brachytherapy). J Contemp Brachytherapy 2018;10(3):260-6.

13. Guinot JL, Rembielak A, Perez-Calatayud J, Rodríguez-Villalba S, Skowronek J, Tagliaferri L, et al. GECESTRO ACROP recommendations in skin brachytherapy. Radiother Oncol 2018;126(3):377-85.

14. Frakulli R, Galuppi A, Cammelli S, Macchia G, Cima S, Gambacorta MA, et al. Brachytherapy in non melanoma skin cancer of eyelid: a systematic review. J Contemp Brachytherapy 2015;7(6):497-502.

15. Tagliaferri L, Bussu F, Rigante M, Gambacorta MA, Autorino R, Mattiucci GC, et al. Endoscopy-guided brachytherapy for sinonasal and nasopharyngeal recurrences. Brachytherapy. 2015;14(3):419-25.

16. Lancellotta V, Kovács G, Tagliaferri L, Perrucci E, Rembielak A, Stingeni L, et al. The role of personalized Interventional Radiotherapy (brachytherapy) in the management of older patients with non-melanoma skin cancer. J Geriatr Oncol. 2018;10:514-17.

17. Lancellotta V, Kovács G, Tagliaferri L, Perrucci E, Colloca G, Valentini V, et al. Age Is Not a Limiting Factor in Interventional Radiotherapy (Brachytherapy) for Patients with Localized Cancer. Biomed Res Int 2018;2018:2178469. 